REsumo

Este artigo aborda o investimento do gozo nas bordas - o recurso a um objeto autístico, a um duplo ou a uma ilha de competência - como estratégia de autotratamento do autista que pode viabilizar tanto o trabalho auto-terapêutico quanto o manejo do tratamento pelo analista.

Descritores: psicanálise; autismo; borda; gozo; tratamento.

\section{ALGUMAS ESTRATÉGIAS DE (AUTO) TRATAMENTO DO AUTISTA}

\author{
Marina Bialer
}

DOl: http://dx.doi.ors/10.11606/issn.1981-1624.v19i1p150-162

\title{
Introdução
}

A importância de bordas protetoras na clínica do autismo tem sido abordada por diferentes linhas teóricas no campo psicanalítico. O estudo clássico de Bettelheim (2008) apontou a existência dessas fronteiras criadas por muitos autistas, objetivando estabelecer uma zona de contato com outras pessoas. Essas bordas protetoras, evidentes na descrição clássica do autismo kanneriano, são analisadas no presente texto, com base nas contribuições dos psicanalistas JeanClaude Maleval (2003, 2007, 2009, 2010, 2011, 2012) e Eric Laurent (2010), que reforçam o fato que as bordas de proteção são dinâmicas e podem se desdobrar na clínica do autismo em objetos autísticos, duplos e ilhas de competência. Além da função protetora, aborda-se a importância do investimento sobre essas bordas como modo de localização do gozo, delimitando bordas que podem ser deslocadas e expandidas, alicerçando estratégias de (auto) tratamento do autista.

- Psicóloga, doutora em Recherches en Psychopathologie et Psychanalyse pela Universidade Paris 7 Denis Diderot. Doutora em Psicologia Clínica pela Universidade de São Paulo (USP), São Paulo, SP, Brasil. 


\section{O investimento sobre as bordas}

As bordas são fronteiras que asseguram a proteção e possibilitam ao autista sair do isolamento autístico e lançar seus "pseudópodes" (Maleval, 2010, p. 252) em direção ao mundo exterior. O investimento nas bordas é uma estratégia defensiva do autista para poder se relacionar com o mundo e, com base nesse lugar seguro e com esse apoio na borda, poder estabelecer várias relações. Tal trabalho, autoterapêutico, é apresentado como uma solução particular de cada autista. Cabe ao analista se inteirar das estratégias defensivas particus lares do autista para auxiliá-lo, quando possível, nesta construção de localização do gozo e de mudança da economia gozosa.

A condensação do gozo em uma borda é uma estratégia autística que pode compensar a falta de ancoragem do gozo no seu corpo, na sua linguagem, permitindo a inscrição de uma perda do gozo controlada pelo próprio autista com base no investimento gozoso em um objeto-borda, do qual o autista tem, ao menos em parte, algum controle. Trata-se de uma compensação da falta da incorporação do significante primordial, permitindo uma localização do gozo, não crochetado aos significantes no autismo.

É importante respeitar as modalidades de investimento nas bordas - a ligação ao objeto autístico, o investimento sobre um duplo e sobre uma ilha de competência -, as quais são importantes estratégias subjetivas no autismo que permitem afrouxar a necessidade de controle de um mundo imutável, totalmente em ordem e favorecem a abertura para o mundo e para as relações sociais. A ruptura precoce e inesperada do mecanismo defensivo do autista pode ter efeitos psiquicamente nefastos, enquanto o respeito à sua finalidade autoterapêutica pode favorecer a abertura do autista e a construção da sua solução singular, adequada ao seu funcionamento psíquico.

\section{Do isolamento à abertura ao laço}

Frequentemente, no primeiro contato com o autista é impactante a prevalência de uma relação na qual o outro está excluído, sendo seu parceiro preferencial um objeto, uma repetição automatizada de sons ou a emissão de sons não direcionados a outro. 
A necessidade de manutenção do familiar no autismo frequentemente se manifesta na tendência à conservação e repetição de atividades, evitando a imprevisibilidade. Frayssinet (2012) descreve as estereotipias envolvendo um gesto ou movimento, aquelas envolvendo rituais cotidianos e, ainda, as que envolvem repetições de pensamentos ou ecolalias.

As estereotipias são uma modalidade de relação com o mundo exterior que permite ao autista um funcionamento denominado "casulo", autocriando barreiras de proteção corporal e de controle das entradas de estímulos externos. Tal bloqueio pode ser compensatório pelo não funcionamento do crivo significante, evidenciando a importância das estereotipias que podem exercer um importante papel organizador e estabilizador no autismo. Frayssinet (2012) sintetiza duas funções estruturais das estereotipias: fornecer bordas de proteção ao corpo protegendo-o dos outros e da presença do Outro, mantendo uma regularidade no mundo e permitindo a recuperação após situações angustiantes - e tratar da relação com a linguagem.

Outro ponto a ser apontado, para além da função de proteção e organização, é o fato de que as estereotipias podem ser a porta de entrada para uma modalidade de apropriação da linguagem. No autismo, a recusa no uso da linguagem para se comunicar está imbricado ao fato de que o autista não sabe como falar: o porquê e o como falar precisam ser construídos.
Neste âmbito, há uma importância estruturante no uso ecolálico da linguagem. Nas repetições ecolálicas, Frayssinet (2012) aponta haver uma repetição do discurso do Outro, mas não uma apropriação. Há um falar sem se inscrever no discurso do Outro, fruto da retenção do objeto voz, da retenção da voz enunciativa. $\mathrm{O}$ uso ecolálico da linguagem é auxiliar para a saída do fechamento autístico, permitindo, nessa repetição do discurso, não ser invadido pela presença do Outro. Evitando a invasão pela presença do Outro, o autista poderá entrar em contato com o que repete ecolalicamente e se relacionar com o que é dito. Embora a ecolalia em si não seja um ato de interação, dado que a ecolalia é a repetição em eco para si mesmo, Frayssinet (2012) aponta com pertinência o fato de que a ecolalia é, para o autista, uma tentativa de se relacionar com o discurso do Outro.

Embora nem todos os autistas precisem passar pela ecolalia pra entrar na linguagem, a ecolalia pode ser uma atividade de função subjetiva estruturante para além da errônea aparência de repetição estéril a ser corrigida ou eliminada (Bialer, 2012). Assim, o uso ecolálico pode ser uma etapa necessária antes de o autista poder entrar em contato com os outros sem ser tomado por excessiva angústia.

É interessante observar que há um trabalho do autista colocado em ato na estereotipia, no automatismo e na ecolalia, os quais são, por mais 
repetitivos e sem relevância que possam parecer aos olhos dos mais desavisados, para o autista de uma extrema importância psíquica.

\section{A inscrição do analista no circuito de automatismos como etapa preliminar a qualquer intervenção}

Para que a ruptura do automatismo seja possível, Jerusalinsky (2010) indica a necessidade de uma etapa preliminar de identificação do analista aos automatismos do autista. Trata-se da construção de um lugar preliminar, necessário, com base no qual uma intervenção é possível. Após a inscrição do analista, é possível estabelecer sutis descontinuidades no circuito do automatismo por meio de alterações do ritmo ou da inclusão de variações pela introdução de fonemas ou movimentos inesperados.

Outra modalidade prevalente na clínica do autismo é a presença de repetições que envolvem o objeto autístico. Nesse sentido, a introdução de pequenas mudanças no circuito do objeto autístico, por meio da extração de um objeto, por exemplo, pode ser crucial no tratamento. No entanto, é preciso salientar a necessidade da intervenção terapêutica anterior : a entrada inicial do analista no circuito do autista. Esta entrada, designada "dócil" pelos psicanalistas Hody e Vose (2008), pode ocorrer por meio de uma ajuda discreta, auxiliando o autista a realizar o seu circuito, por exemplo, ao pegar um objeto que caiu no chão e colocar de volta no circuito. Tal entrada dócil pode ser favorecida pela presença do analista na mesma sala, ao lado do autista, ocupando-se de outra coisa, não focado no autista, mas em disponibilidade, permitindo ao autista inscrevê-lo no seu tempo. Dada a particularidade do autista na retenção do objeto pulsional e evasiva da dimensão gozosa da linguagem, o manejo do gozo via objeto, via circuito do objeto autístico, pode ser uma etapa essencial para o tratamento no autismo.

\section{O objeto autístico e o duplo}

A relação privilegiada do autista com um objeto alicerça, com significativa frequência, um movimento de ligamento/desligamento equivalente a um processo de vitalização. Perrin (2008) descreve o percurso no tratamento de um autista de cinco anos das alternâncias de on/off, quando a criança estava ligada a objetos-veículos, eles lhe davam uma animação libidinal que, quando desconectada, o corpo do autista ficava desvitalizado. A análise do lugar da analista neste caso clínico fornece algumas indicações sobre a entrada possível do analista no tratamento do autista: em um primeiro momento, a analista 
intervém como parceira do autista, ajudando-o em sua interação on/ off com os veículos; em um segundo momento, o próprio autista convida o analista para participar de outras atividades.

No caso citado por Perrin, a estratégia de recurso a um objeto autístico (veículo) e a Outro em posição de duplo (a analista) caracterizam estratégias por meio das quais o autista trata o gozo ilimitado, permitindo uma conexão ao gozo, sem ser totalmente invadido. $\mathrm{O}$ respeito à necessidade de ter o controle da perda do próprio gozo pode ser essencial para a condução do tratamento no autismo. $\mathrm{O}$ apoio alienante em um objeto-borda pode ser uma resposta necessária, vital para a saída do autista do fechamento autístico. É com base no investimento nas bordas de um objeto e/ou de um duplo que o autista pode inventar seu objeto-apêndice no qual se localiza o gozo transbordante. É importante ressaltar que tal investimento permite situar um gozo que, ilimitado, debordante, é extremamente ameaçador para o autista. A localização do gozo em um objeto-borda permite ao autista uma relação de controle em relação à própria economia de gozo, fixando o gozo, que outrora era totalmente ameaçador, e possibilitando ao autista novas soluções para se relacionar com o próprio gozo.

O investimento nas bordas é um autotratamento que o autista dá ao gozo ilimitado. Além desse importante papel de localização do gozo, a construção do objeto-borda e do outro-duplo-borda pode permitir ao autista, por meio de uma identificação imaginária desse outro e da extração de um objeto-gozo desse outro, concretizar uma estratégia autística para incorporar um traço, uma característica do outro, especialmente características ligadas à vitalidade e à animação libidinal.

Um interessante caso clínico descrito por Fauvel (2009) apresenta uma menina autista que retira os sapatos dos pés da sua psicanalista e dos demais integrantes da equipe terapêutica. De posse dos sapatos do outro-duplo, essa criança adquire uma vitalidade, uma dinâmica, e consegue manter esse dinamismo sem precisar estar colado a um outro-duplo. Ao longo do tratamento, há um deslocamento da ligação aos sapatos dos membros da equipe para a ligação a uma boneca com sapatos, na companhia da qual ela pode dispensar a companhia de um adulto.

A necessidade de controle do objeto / duplo precisa ser tolerada e respeitada para que o objeto-duplo funcione como borda protetora, na qual é localizada o gozo debordante. Há uma etapa na qual 
o outro-borda é necessário como apoio presente para que o autista possa se relacionar com os outros e com o mundo. Nessa etapa, para que o autista possa desenvolver suas estratégias de autotratamento do gozo, ele necessita do apoio auxiliar para a saída do fechamento autístico e da necessidade compulsiva de manutenção de um ambiente imutável. Tal etapa, na qual a dependência do duplo é predominante, e se for respeitada, o autista pode caminhar em direção a uma etapa na qual ele pode suprimir a necessidade do outro auxiliar.

\section{O lugar do analista-parceiro}

$\mathrm{Na}$ transferência, o analista ao ocupar o lugar do duplo do autista pode ser uma etapa preliminar, necessária, para o estabelecimento por parte do autista de uma relação não intrusiva com os outros e com o mundo. A sinalização da importância do investimento no duplo pode indicar um lugar possível para o analista no tratamento do autista. Trata-se de uma posição de parceiro, auxiliando o autista nas suas criações de autotratamento do gozo debordante pelo investimento nas bordas. Vale a pena destacar a ressalva pertinentemente levantada por Perrin (2009) sobre o fato de que o lugar do analista como suporte da imagem do duplo não equivale a um apoio dado pelo ego forte do clínico. O foco da relação com o analista não deve ser no ego do analista, mas na sua presença marcada pelo desejo, por um saber não totalitário e por um corpo faltante. $\mathrm{O}$ analista pode favorecer o tratamento do autista ao auxiliar as soluções singulares que cada autista inventa, ocupando o lugar de um duplo não demasiadamente presente, mas que pode fazer barreira ao gozo em excesso quando necessário.

Trata-se, pois, de uma presença dócil, não invasiva, mas capaz de atos de limitação do gozo invasivo. Maleval (2012) acrescenta um importante aspecto que deve ser considerado: apoiado nos interesses do autista, seguindo as soluções singulares de cada autista, o analista precisa com alguma frequência forçar sutilmente, docemente, a fim de auxiliar o autista e suscitar movimento na sua dinâmica libidinal. Tal forçada visa auxiliar o autista a desenvolver estratégias de compensação da não regulação do gozo pela linguagem da qual decorre sua necessidade de investimento sobre as bordas para a criação de invenções singulares, autoterapêuticas. 
Após o investimento sobre a borda e a inserção do analista como um parceiro que auxilia o autista na estratégia de investimento do gozo nas bordas, o analista pode realizar intervenções sobre os automatismos, as estereotipias e no relacionamento com o objeto autístico, realizando intervenções que permitam inscrições de elementos diferenciais, de alteridade, que podem ser um importante passo em direção a uma mudança da economia do gozo. Após a inscrição de um elemento diferencial, por exemplo, a inclusão ou a exclusão de um veículo (com no caso de Perrrin), pôde haver espaço para o estabelecimento de um circuito de troca, de uma circulação deste objeto extraído, ou incluído, viabilizando a inscrição dessa alteração do circuito do gozo. Trata-se de um esboço de regulação do sistema de tratamento do gozo, tal qual pode-se observar no exemplo a seguir.

Após um período inicial de fechamento autístico, Damave e Hosselet (2000) descrevem fortes angústias em um jovem autista que perduram até a adoção de pedaços de tecidos com os quais ele se envolve e se acalma; após tal adoção, ele estabelece um circuito de trocas realizado com um cachecol dado pela equipe de analistas: o objeto vai dele para o Outro e do Outro para ele. Tal transformação de um objeto em cedível, passível de troca com os outros, permite passar pelas bordas de proteção autística, mudando discretamente a anterior economia de gozo.

O trabalho sobre os circuitos - as trocas com base nessas bordas nas quais o autista investe - pode permitir um alargamento, uma extensão dessas bordas, tal como assinalado por Laurent (2010). No entanto, enquanto Laurent focaliza o investimento sobre a borda em relação à mutação do encapsulamento autístico para um encapsulamento móvel, que permite interações dinâmicas com os outros e com o mundo, o psicanalista Maleval (2012) enfatiza a extensão da conceituação de investimento sobre as bordas no autismo para abarcar não somente a modalidade designada de encapsulamento - de relação do autista ao objeto autístico -, mas também as modalidades de relação com o duplo e com as ilhas de competência.

\section{A ilha de competência no autismo}

A ilha de competência é a construção de um domínio de conhecimento, a aquisição de uma competência desenvolvida em 
uma área de saber delimitada, a qual pode embasar a construção de um "Outro de suplência" (Maleval, 2003, p. 206). O Outro de suplência é um método diferente de tratamento do gozo pautado no investimento do repertório de informações acumuladas e nas competências adquiridas, cuja constituição pode ser favorecida pela animação libidinal e pela capacidade de sair do fechamento autístico, geralmente obtidas após o estabelecimento de relações privilegiadas com o objeto autístico e com o duplo.

Esse repertório de conhecimentos do autista é uma construção equivalente a uma biblioteca de experiências construídas com base em signos assimilados, preservando a rigidez, especialmente em relação à utilização da ironia, das metáforas e das nuances implícitas. A prevalência da relação ao referente, a não aquisição da flexibilidade significante encontra uma compensação na criação de conhecimentos pautados na acumulação de fatos alicerçada em uma capacidade de memorização excepcionalmente elaborada. Tal repertório de informações pode culminar em Outro de signos, também designado "Outro de síntese” (Maleval, 2010, p. 255), cujo saber pode culminar em Outro de suplência, concretizando uma importante estratégia de autotratamento.

Vale ressaltar que o conhecimento construído em torno da ilha de competência é o resultado de uma escolha de aprendizagem do autista, pautado na sua singularidade, e que pode pos- 
sibilitar um crescimento afetivo, cognitivo e social, imbricando tais áreas em uma solução original, possibilitando uma mudança subjetiva. O esforço de construção desse arcabouço de informações pode ser uma importante ferramenta de autotratamento criada pelo autista. Mesmo marcada pela prevalência do registro de signos, tal construção linguística pode permitir a utilização da linguagem e a invenção do amparo do Outro de suplência. Este Outro, embora rígido, sem a flexibilidade do significante, não dificulta o laço social; ao contrário, é uma importante via de acesso ao mundo, facilitadora do contato do autista com os outros.

A assimilação dos signos, correlata à entrada nas bordas da linguagem pelo autista, pode ser feita pela leitura, ao assistir televisão, em contato com o mundo, mas em uma forma de assimilação que permita manter à distância o risco da invasão pelo gozo implicado em uma incorporação significante da linguagem, recusada pelo autista. Daí a prevalência dada aos refeĐ rentes concretos da linguagem, aos signos e ícones, e a evasiva da polissemia significante. De tais associações, privilegiando a referência fixa do signo em detrimento da maleabilidade fonética do som, podem surgir associações metonímicas originais, conforme ressaltado por Maleval (2009). A perseverança de tomar literalmente o que foi dito, a dificuldade em generalizar situações aprendidas, a atração pelas regras e pelas estruturas fixas podem ser algumas das manifestações dessa relação do autista com a linguagem, alicerçada na prevalência do signo em detrimento do significante.

\section{A existência do significante primordial "vago" no autismo}

Esta relação singular do autista à linguagem foi descrita com maestria por Maleval (2007), que aponta nuances que complexificam a leitura do lugar do autista no campo linguístico. A evasiva da enunciação, que implicaria uma perda gozosa do objeto voz, pode culminar em um mutismo, mas também pode se apresentar na construção de uma língua "funcional” (Maleval, 2011, p. 84), pautada na acumulação de fatos. Tal língua funcional, informativa, factual, pode ser manifestada em uma comunicação dos fatos, 
das informações, sem expressão pessoal, sem implicação da voz enquanto objeto de gozo. Tal língua funcional é frequentemente expressa por uma voz mecânica, que permite ao autista se comunicar com os outros, desde que os afetos sejam desconsiderados. A prevalência da recusa da linguagem significante é uma estratégia defensiva, uma recusa à alienação plena ao Outro da linguagem; no entanto, Maleval demonstra com toda pertinência que o autista tem acesso a esse campo de linguagem, significante, embora se estruture, justamente, na recusa dele.

A existência do campo significante no autista pode ser evidenciada na presença de esporádicas enunciações marcadas de gozo que irrompem, com angústia marcante, sem finalidade de comunicação. São frases que não tem origem em um longo processo intelectual, mas que saem do mais íntimo do autista, são expressões marcadas de afetos, enunciações fugazes que rompem momentaneamente a retenção do objeto voz gozoso, surgindo de maneira quase explosiva, produtora de intensa angústia no autista, podendo ser seguidas de uma evasiva em reconhecer o que se disse como próprio ou de um novo fechamento em si mesmo para tentar escapar do que foi expresso nestas expressões fugazes, nas quais o autista escuta a própria voz marcada de afeto. Outra manifestação frequente no autista é a existência de uma língua privada "mais conectada à melodia que à significação" (Maleval, 2009, p.
249), que não objetiva a comunicação, mas que alicerça um prazer, um gozo solitário no manejo da língua.

Deste modo, a prevalência dos signos pode se alternar ao surgimento de tais frases eruptivas, espontâneas, caracterizando a relação de borda do autista à linguagem. É o retrato da assimilação no campo significante primordial, e não de uma incorporação, sendo tal relação identificada por Perrin (2010) pela existência de um significante vago no autismo. Metaforicamente seria um assento de trem: $\mathrm{o}$ autista tem o assento à sua disposição, mas prefere ficar em pé durante a viagem, mesmo havendo a inscrição do assento significante.

Outra estratégia que pode ser desenvolvida pelo autista para remediar a evasiva ao contato com a dimensão gozosa da linguagem é a utilização de métodos que permitam falar, mantendo o gozo à distância. Há, por exemplo, o falar por procuração, utilizando outra pessoa, um duplo que suporta a função de enunciação caracterizando, uma "enunciação artificial” (Maleval, 2011, p. 90) como uma marionete que protege o autista, permitindo-lhe se comunicar à distância, protegido pela presença do duplo. Tal desvio pela voz do outro permite ao autista, muitas vezes, emitir enunciações pessoais, autorizando-se a falar, desde que investindo na borda/ duplo.

Dessas constatações do funcionamento do autista em relação à linguagem, Maleval (2009) aponta algumas 
importantes indicações para o tratamento: dado a retenção do objeto vOZ no autismo e da consequente dificuldade em habitar subjetivamente as enunciações dirigidas a outro, o autista é particularmente mais suscetível às palavras "lúdicas" (p. 245) do que às palavras imperativas, é mais suscetível às canções, às falas do analista ou de qualquer outro formuladas de maneira tangencial, do que de maneira direta, demandante. Neste mesmo sentido, Perrin (2011) formula a importância de uma "indiferença calculada" (p. 100), pautando intervenções que privilegiem um fazer-se ausente na enunciação ao se endereçar ao autista, concomitantemente a uma discrição no posicionamento do corpo.

\section{Conclusão}

Considerar tais manifestações autísticas no campo da linguagem como estratégias necessárias para a dinâmica subjetiva do autista pode permitir ao analista uma melhor escuta do autista e uma condução mais singularizada do tratamento. O desdobramento em uma língua funcional, uma língua solitária e em expressões irruptivas, explosivas, são três retratos da estrutura autística. Tais manifestações são estratégias criadas pelo autista para se autorizar a falar, para sair de um fechamento autístico e poder se relacionar com o mundo, com os outros. Respeitar as condições nas quais uma 
fala é possível para o autista fornece importantes indicações sobre as maneiras viáveis e adequadas para intervir no tratamento.

A evasiva do objeto pulsional voz enquanto inscrição do gozo no significante é característica do autismo. São várias as modalidades de uso da linguagem para evitar a dimensão gozosa da linguagem. Neste artigo abordou-se a importância dessas formas singulares de manejo do campo da linguagem. Tomou-se como base a retenção do objeto pulsional voz no autismo para abordar percursos de ruptura dos automatismos e do encapsulamento, analisando as estratégias de investimento em objetos autísticos, duplos, ilhas de competência e repertórios de signos que podem desembocar em soluções autísticas singulares, mudanças subjetivas e uma maior autonomia social e subjetiva.

Conclui-se enfatizando que a ligação do autista ao objeto-borda, duplo-borda e ilha-borda não deve ser, portanto, combatida, mas sustentada. É importante, justamente, considerar os interesses particulares de cada autista, respeitando a zona de proteção que ele criou para se proteger de uma angústia devastadora. Nesse sentido, pode-se afirmar que a importância do investimento sobre a borda no autismo, seja um objeto, um duplo ou uma competência, embasa um contra-argumento às técnicas terapêuticas que preconizam a retirada dos objetos autísticos considerados destrutivos e nocivos, que formulam a relação ao duplo como intrisicamente destrutiva e que procuram corrigir e mudar a fixação obsessiva do autista por uma área de conhecimento, desconsiderando a importância subjetiva desses investimentos. A direção do tratamento de um autista deve justamente se balizar tanto nestas estratégias particulares necessárias para o autista operacionalizar a localização do gozo, quanto nas soluções singulares inventadas pelo autista, as quais podem ser potencializadas por um laço transferencial atento às particularidades do autismo.

SOME STRATEGIES OF (SELF) TREATMENT BY THE AUTISTIC

\section{Abstract}

This article discusses the investment of the jouissance at the bords - the use of an autistic object, a double or an island of competence - as strategies of self-treatment by the autistic that can facilitate both a (self-) therapeutic work and the orientation of treatment by the analyst.

Index terms: psychoanalysis; autisme; bords; jouissance; treatment.

ALGUNAS ESTRATÉGLAS PARA EL (AUTO) TRATAMIENTO DEL AUTISTA

\section{REsumen}

En este articulo se analiza la movilización del goce en los bordes - el uso de un objeto autístico, un doble ou un islote de competencia - como estrategias para el auto-tratamiento del autista que puden facilitar tanto un trabajo auto-terapéutico como el manejo del tratamiento por el analista.

Palabras clave: psicoanálisis; autismo; borde; goce; tratamiento. 


\section{REFERÊNCIAS}

Bettelheim, B. (2008). La forteresse vide: l'autisme infantile et la naissance du soi. Saint-Amand, França: Éditions Gallimard.

Bialer, M. (2012). Le corps dans l'autisme et dans la schizophrénie. Tese de Doutorado, École Doctorale Recherches en Psychanalyse, Université Paris 7 Denis Diderot, Paris / Instituto de Psicologia, Universidade de São Paulo, São Paulo.

Damave, M., \& Hosselet, V. (2000). Où se situe le caprice? Les Feuillets du Courtil, 18/19, 243-247.

Fauvel, I. (2009). La beauté bottée. In J-C. Maleval (Org.), L'autiste, son double et son objet (pp. 197-210). Rennes, França: Presses Universitaires de Rennes.

Frayssinet, M. (2012). Autisme et schizophrénie. Tese de Doutorado, École Doctorale Recherches en Psychopathologie, Université Rennes 2, Rennes.

Hody, F., \& Vose, P. (2008). Se faire un corps. Chutes et séries. La Petite Girafe, 27, 58-60.

Jersusalinsky, A. (2010). Consideraçóes preliminares a todo tratamento possível do autismo. Revista Psicologia Argumento, 28 (61), 121-125.

Laurent, E. (2010). Les futurs des spectres de l'autisme. In B. Halleux (Org.), Quelque chose à dire à l'enfant autiste: pratique à plusieurs à l'Antenne 110 (pp. 223-236). Paris: Éditions Michèle.

Maleval, J-C. (2003). De l'objet autistique à la machine. Les suppléances du signe. In F. Hulak (Org.), Pensée psychotique et création de systèmes: la machine mise à nu (pp.197-217). Ramonville Saint-Agne, França: Éditions Érès.

Maleval, J-C. (2007). "Plutôt verbeux" les autistes. La Cause Freudienne, 66, 127-140.

Maleval, J-C. (2009). L'autiste et sa voix. Paris: Éditions du Seuil.

Maleval, J-C. (2010). Quelqu'un qui puisse lâcher prise. In B. Halleux (Org.), Quelque chose à dire à l'enfant autiste: Pratique à plusieurs à l'Antenne 110 (pp. 237-259). Paris: Éditions Michele.

Maleval, J-C. (2011). Langue verbeuse, langue factuelle et phrases spontanées chez l'autiste. La Cause Freudienne, 78, 77-92.

Maleval, J-C. (2012). Écoutez les autistes! Paris: Navarin Éditeur.

Perrin, M. (2008). Des objets et des liens. "Baf vardage" avec un petit lion dans le miroir. La Petite Girafe, 27, 64-66.

Perrin, M. (2009). Construction d'une dynay mique autistique de l'autogire à la machine à laver. In J-C. Maleval (Org.), L'autiste, son double et son objet (pp. 69-100). Rennes, França: Presses Universitaires de Rennes.

Perrin, M. (2010). L'autisme: spécificités structurales. L'avant-gardisme lacanien sur l'autisme et ses enseignements. In L. Jodeau-Belle \& L. Ottavi (Orgs.), Les fondamentaux de la psychanalyse lacanienne: repères épistémologiques, conceptuels et cliniques (pp. 337-356). Rennes, França: Presses Universitaires de Rennes.

Perrin, M. (2011). L'autiste a-t-il quelque chose à dire ? Transfert autistique et cont duite du traitement. La Cause Freudienne, 78, 93-102.

mbialer@hotmail.com

Rua Dr. Homem de Melo, 407/71 05007-001 - São Paulo - SP - Brasil.

Recebido em maio/2013. Aceito em dezembro/ 2013. 